\title{
INVESTIGAÇÕES GEOFÍSICAS DE SUPERFÍCIE E DE POÇO NO SÍTIO CONTROLADO DE GEOFÍSICA RASA DO IAG-USP
}

\author{
Jorge Luís Porsani ${ }^{1}$, Welitom Rodrigues Borges ${ }^{2}$, Vagner Roberto Elis ${ }^{3}$, Liliana Alcazar Diogo ${ }^{4}$, \\ Francisco Yukio Hiodo ${ }^{5}$, Antonio Marrano ${ }^{6}$ e Carlos Alberto Birelli7 \\ Recebido em 10 setembro, 2004 / Aceito em 25 novembro, 2004 \\ Received September 10, 2004 / Accepted November 25, 2004
}

ABSTRACT. This paper presents the results obtained from surface and borehole geophysical investigations carried out at the Shallow Geophysical Test Site of IAGUSP. The main objective was to characterize the sediments and the top of basement. The area is constituted by sandy-clay sediments of São Paulo Basin (São Paulo and Resend Formations) on the granite-gneiss basement with different degrees of weathering. In the area of studies, three boreholes were drilled for geological and geophysical research purposes (pioneer in Brazil). These boreholes were used to verify the stratigraphy, to collect the sample for laboratory measurements, to calibrate the results of surface geophysics and to carry out well logging. The surface methods used were: seismic (reflection and refraction), electric-resistivity (profiling and vertical electric sounding) and GPR-Ground Penetrating Radar. The integration of results show excellent agreement and allow constructing a geological-geophysical model for the site which is at the border of São Paulo sedimentary basin. Moreover, the various geophysics methods, commonly used in geological, geotechnical and environmental researches, have been tested under controlled conditions.

Keywords: Shallow Geophysical Test Site of IAG-USP, São Paulo sedimentary basin; Geophysical methods of surface and borehole; Seismic (reflection and refraction); Electric-resistivity (electric survey and vertical electric sounding); GPR-Ground Penetrating Radar.

RESUMO. Este trabalho sintetiza os resultados de investigações geofísicas de superfície e de poço realizadas no Sítio Controlado de Geofísica Rasa do IAG-USP, visando caracterizar os sedimentos e o topo do embasamento. A área é constituída por sedimentos areno-argilosos da Bacia de São Paulo (Formações São Paulo e Resende) sobrepostos ao embasamento granito-gnáissico com diferentes graus de intemperização. Na área de estudos, também denominada de campo de provas do IAG, foram perfurados três poços para pesquisas geológicas e geofísicas (pioneiros no Brasil), visando verificar a litoestratigrafia, coleta de amostras de calha, calibrar os resultados e realizar as perfilagens geofísicas. Foram utilizados os seguintes métodos: sísmica rasa (reflexão e refração), eletrorresistividade (caminhamento elétrico e sondagem elétrica vertical) e GPR-Ground Penetrating Radar. A integração dos resultados mostrou uma excelente concordância e permitiu elaborar um modelo geológico-geofísico para este ponto da Bacia Sedimentar de São Paulo, bem como testar, em condições controladas de campo, os diversos métodos geofísicos usados rotineiramente em estudos geológicos, geotécnicos e ambientais.

Palavras-chave: SCGR-IAG; Sítio Controlado de Geofísica Rasa do IAG-USP; Bacia sedimentar de São Paulo; Métodos geofísicos de superfície e de poço; Sísmica (reflexão e refração); Eletrorresistividade (caminhamento elétrico e sondagem elétrica vertical); GPR-Ground Penetrating Radar.

${ }^{1}$ IAG-USP - Instituto de Astronomia, Geofísica e Ciências Atmosféricas da Universidade de São Paulo, Rua do Matão, 1226, Cidade Universitária - 05508-090 São Paulo, SP, Brazil. Tel: (55-11) 3091-4734; Fax: (55-11) 3091-5034 - E-mail: porsani@iag.usp.br

2Pós-Graduação em Geofísica - IAG/USP, Rua do Matão, 1226, Cidade Universitária - 05508-090 São Paulo, SP, Brazil. Tel: (11) 3091-2792; Fax: (11) $3091-5034$

-E-mail: welitom@iag.usp.br

3 IAG-USP - Departamento de Geofísica, Rua do Matão, 1226, Cidade Universitária - 05508-090 São Paulo, SP, Brazil. Tel: (11) 3091-4734; Fax: (11) 3091-5034

-E-mail: vagnelis@iag.usp.br

4 IAG/USP - Departamento de Geofísica, Rua do Matão, 1226, Cidade Universitária, Butantã - 05508-090 São Paulo, SP, Brazil. Tel: (11) 3091-4672; Fax: (11) 3091-5034 - E-mail: liliana@iag.usp.br

5 IAG-USP - Departamento de Geofísica, Rua do Matão, 1226, Cidade Universitária - 05508-090 São Paulo, SP, Brazil. Tel: (11) 3091-4777; Fax: (11) 3091-5034 -E-mail: francisc@iag.usp.br

6 Instituto de Pesquisas Tecnológicas do Estado de São Paulo (IPT), Av. Prof. Almeida Prado, 532 - Prédio 59 - 05508-901 São Paulo, SP, Brazil. Telefax: (11) 3767-4767 - E-mail: amarrano@ipt.br

7 Instituto de Pesquisas Tecnológicas do Estado de São Paulo S/A-IPT, Divisão de Geologia, Laboratório de Geofísica Aplicada, Cidade Universitária, Av. Prof. Almeida Prado, 532, Butantã - 05508-901 São Paulo, SP, Brazil. Telefax: (11) 3767-4767 -E-mail: birelli@ipt.br 


\section{INTRODUÇÃO E OBJETIVOS}

0 presente trabalho sintetiza os resultados das investigações geofísicas de superfície e de poço realizados no Sítio Controlado de Geofísica Rasa, no campus universitário da USP. A interpretação dos resultados foi realizada de maneira integrada com os dados litológicos dos poços, permitindo testar em condições controladas de campo e avaliar de forma comparativa, os diversos métodos geofísicos usados rotineiramente em estudos geológicos, geotécnicos e ambientais.

A área utilizada para as investigações geofísicas de superfície e de poço está inserida no âmbito da Bacia Sedimentar de São Paulo, na qual é uma das unidades integrantes do Rift Continental do Sudeste do Brasil. Exibe forma irregular, aproximadamente elíptica, com uma área total de aproximadamente $1000 \mathrm{~km}^{2}$, sendo drenada principalmente pelo rio Tietê e, secundariamente, pelos rios Pinheiros, Tamanduateí e seus tributários (Riccomini, 1989, 1992).

Dentre as bacias tafrogênicas do Sudeste Brasileiro, a Bacia de São Paulo é uma das unidades mais bem estudadas do ponto de vista geológico e geotécnico. A localização da cidade de São Paulo, assentada em grande parte sobre essa bacia, e a implantação de importantes obras, como a construção do Metrô e do aeroporto internacional de Guarulhos, favoreceram sobremaneira o conhecimento de sua geologia.

0 conhecimento geológico da bacia foi obtido principalmente através de informações diretas de escavações, sondagens e através de mapeamentos geológicos realizados nas décadas de 70 e 80. Devido ao desenvolvimento tecnológico e a crescente urbanização da grande São Paulo, o solo exposto da bacia foi pavimentado e impermeabilizado, tornando difícil o estudo da bacia através de levantamentos geológicos e de investigações diretas. Deste modo, os métodos geofísicos de investigação indireta tornaram-se ferramentas indispensáveis para o conhecimento geológico e geotécnico da Bacia de São Paulo.

Com o propósito de estudar e caracterizar o subsolo da borda da Bacia de São Paulo, o campus da Capital da Universidade de São Paulo (USP) vem sendo utilizado como laboratório de pesquisas geofísicas pelo Departamento de Geofísica do Instituto de Astronomia, Geofísica e Ciências Atmosféricas (IAG) desde 1993 (Mendonça et al., 1999). Nessas pesquisas, foram empregados os seguintes métodos geofísicos: sísmica de refração rasa, eletrorresistividade, magnetometria, eletromagnético indutivo e GPR-Ground Penetrating Radar. Esses estudos mostraram como problemas ambientais, ou de investigação rasa aplicada à engenharia, podem tornar-se complexos com relação à interpretação dos dados. Apesar da boa concordância daqueles resultados, dúvidas sobre algumas feições geológicas persistiam. Essas dúvidas motivaram-nos a definir uma área de testes controlados de geofísica rasa onde diversos métodos poderiam ser executados e comparados aos dados de poços e às propriedades físicas conhecidas.

Dando continuidade às pesquisas iniciadas no passado, este trabalho tem como objetivo principal realizar uma interpretação integrada de dados geofísicos de superfície e de poço, e litologia de poços, em uma área de "Testes Controlados de Geofísica Rasa do IAG/USP". Para tanto, os trabalhos de campo foram concentrados numa área pequena (Figura 1). Os métodos geofísicos utilizados foram: sísmica rasa (refração e reflexão), eletrorresistividade (sondagem elétrica vertical e caminhamento elétrico) e GPR-Ground Penetrating Radar. Os resultados obtidos foram promissores, eliminaram as ambigüidades inerentes à interpretação dos dados de superfície e serão úteis para futuras calibrações de equipamentos geofísicos.

\section{Trabalhos anteriores no campus da USP}

0 campus da Universidade de São Paulo está instalado na borda da Bacia Sedimentar de São Paulo e vem sendo alvo de pesquisas geológicas e geofísicas desde a década de 90. Iritani et al. (1990) e Iritani (1993) com o objetivo de estudar o potencial hidrogeológico do campus da USP-São Paulo, integraram os dados de perfuração de 17 poços tubulares profundos e 17 sondagens elétricas verticais. Os resultados deram origem a um mapa de isópacas dos sedimentos da Bacia de São Paulo e mostraram que o pacote sedimentar apresenta um espessamento em direção ao Rio Pinheiros, atingindo cerca de $70 \mathrm{~m}$ de espessura. Por outro lado, o afinamento na espessura dos sedimentos ocorre na parte sul e sudoeste do campus. Este afinamento é confirmado por anomalias gravimétricas, ocorrência de afloramentos e pelo alto topográfico.

Taioli (1992) por meio de um perfil sísmico de reflexão verificou que o embasamento da Bacia de São Paulo sofre uma inflexão em direção ao Rio Pinheiros. Os resultados foram calibrados com base em informações litológicas de dois poços de observação.

A partir de 1997, a área em frente ao Instituto de Astronomia, Geofísica e Ciências Atmosféricas (IAG/USP) passou a ser utilizada sistematicamente como laboratório de aulas práticas de Geofísica Aplicada do IAG. Os resultados preliminares de levantamentos magnéticos, elétricos, eletromagnéticos indutivos, GPR e sísmicos estão apresentados em Mendonça et al. (1999).

Le Diagon (2000) realizou perfis de refração e reflexão sísmica 


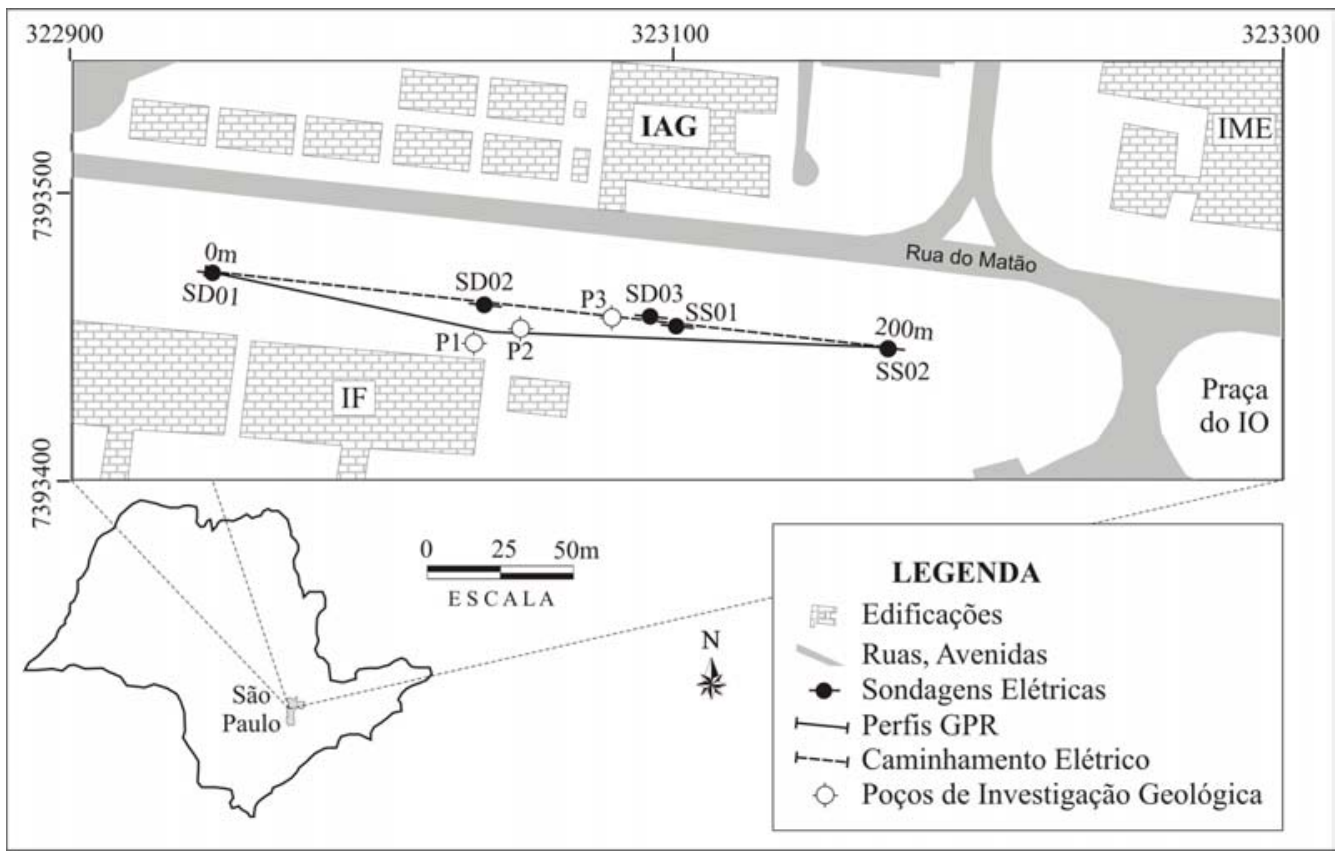

Figura 1 - Mapa de localização da área estudada, posição dos perfis geofísicos, das sondagens elétricas verticais e dos poços para pesquisas geofísicas.

Figure 1 - Location map of the studied area, positions of geophysical profiles position, vertical electric soundings and wells for geophysical researches.

rasa no local de estudos na direção NW-SE. Integrando os dados de reflexão e de refração obteve modelos superestimado ( $v$ = $1967 \mathrm{~m} / \mathrm{s}$ ) e subestimado $(\mathrm{V}=1650 \mathrm{~m} / \mathrm{s})$ da velocidade da onda sísmica compressional (P) no pacote de sedimentos sobreposto ao embasamento. Os resultados mostraram que 0 embasamento mergulha para NW, com uma profundidade de $35 \mathrm{~m}$ na parte mais rasa e em torno de $55 \mathrm{~m}$ na parte mais profunda.

Borges \& Porsani (2001) utilizando GPR e eletrorresistividade caracterizaram a estrutura geoelétrica rasa na área do Sítio Controlado de Geofísica Rasa do IAG/USP. Os resultados apresentaram uma boa concordância com as informações litológicas dos poços.

Borges \& Porsani (2003) através dos métodos eletromagnéticos Slingran (EM38) e GPR-Ground Penetrating Radar, definiram 0 background geoelétrico da área onde foi instalado 0 Sítio Controlado de Geofísica Rasa do IAG/USP. Nesta área, vários alvos com propriedades físicas distintas foram enterrados em diferentes profundidades visando estudos geotécnicos, ambientais e arqueológicos.

Rodrigues \& Porsani (2003) utilizaram simulações numéricas GPR 2D para caracterizar tambores plásticos enterrados no Sítio Controlado do IAG. Os resultados preliminares mostraram padrões de reflexões típicos para tambores preenchidos com ar, água doce ou água salgada.

\section{GEOLOGIA LOCAL E PERFILAGEM DOS POÇOS}

A área utilizada para os testes de campo, situada na borda da Bacia Sedimentar de São Paulo, é constituída predominantemente por sedimentos areno-argilosos de idade terciária (Formações Resende e São Paulo), sobrepostos ao embasamento granitognáissico de idade pré-cambriana, com diferentes graus de intemperização.

Para se realizar as perfilagens geofísicas foram perfurados três poços (únicos no Brasil) com $80 \mathrm{~m}$ de profundidade, 4" de diâmetro e revestidos com tubos de PVC geomecânico ao longo de todo o pacote sedimentar. Os dados dos poços mostram que a espessura dos sedimentos na área da pesquisa não ultrapassa $53 \mathrm{~m}$. A Figura 1 mostra a localização da área de estudos com a posição dos três poços perfurados para pesquisas geológicas e geofísicas. A correlação entre as colunas litoestratigráficas dos três poços está apresentada na Figura 2. Foram identificadas as seguintes unidades geológico-geotécnicas, descritas resumidamente a partir da superfície:

Aterro: caracterizado por argila arenosa a siltosa, com alguns níveis intercalados de silte, ora argiloso, ora arenoso, predominantemente de cor escura e, eventualmente com presença de matéria orgânica. As espessuras prospectadas variaram de $4,5 \mathrm{~m}$ a 6,0 m; 


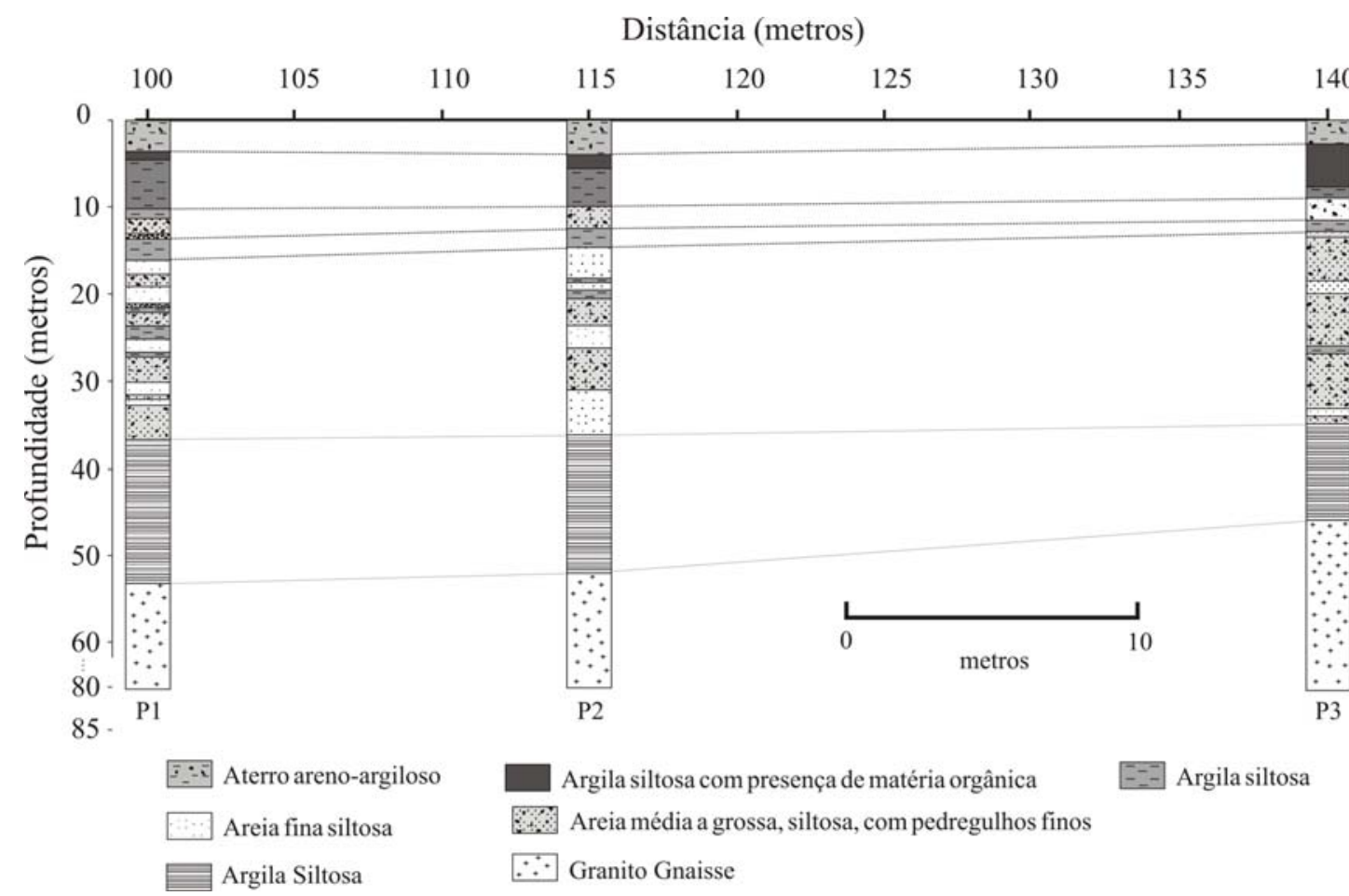

Figura 2 - Correlação entre os perfis litológicos dos poços.

Figure 2 - Correlation between lithologic profiles of the wells.

Sedimentos da Bacia de São Paulo: compõem um pacote sedimentar constituído por horizontes argilosos e arenosos, intercalados entre si. Este pacote pode ser dividido em dois níveis:

i) nível superior: tem espessura variando de $11 \mathrm{~m}$ (poço P2) a 14,5 m (poço P1), sendo constituído por dois horizontes de argila siltosa, intercalados com dois horizontes de areia de granulação média a grossa, siltosa, com seixos de quartzo e concreções limoníticas. A profundidade do nível d'água, medida em novembro de 2000, variou entre 5 e $7 \mathrm{~m}$ de profundidade. A presença de concreções limoníticas, além da freqüência da intercalação entre horizontes arenosos e argilosos, serviram como critério para associar este nível aos sedimentos da Formação São Paulo (Ricomini, 1989);

ii) nível inferior: tem espessura variando de $29,2 \mathrm{~m}$ (poço P1) a 31,5 m (poço P2), sendo constituído por um horizonte arenoso sobrejacente a um horizonte argiloso. 0 horizonte arenoso, com aproximadamente $18 \mathrm{~m}$ de espessura, é composto de areia, granulação média a grossa, predominantemente siltosa, com seixos de quartzo e fragmentos angulosos de feldspato. 0 horizonte argiloso, com espessura média em torno de $13 \mathrm{~m}$, é composto de argila siltosa, marrom avermelhada escura, com manchas cinza clara. A presença de fragmentos angulosos de feldspato e a ocorrência de dois espessos horizontes serviram como critério para associar este nível aos sedimentos da Formação Resende (Ricomini, 1989);

Embasamento cristalino: é constituído por migmatito com estrutura estromatíitica predominante, sendo que os testemunhos foram descritos pelo termo "granito-gnaisse". 0 topo rochoso está a profundidades de $53 \mathrm{~m}$ (poços P1 e P2) e $46 \mathrm{~m}$ (poço P3). A parte superior, com espessura média de $4 \mathrm{~m}$, apresentase muito alterado e fraturado. Abaixo desta camada, a rocha possui coloração cinza escura a rósea, por vezes com níveis cinza claro a amarelado; apresenta-se praticamente sã, coerente e pouco fraturada (em geral, menos de 5 fraturas $/ \mathrm{m}$ ), com eventuais intercalações de rocha medianamente alterada e medianamente fraturada ( 5 a 10 fraturas $/ \mathrm{m}$ ), associadas a níveis em que as fraturas apresentam as paredes alteradas e com película de oxidação. Atéa profundidade máxima prospectada no maciço rochoso (34 m no poço P3), foi possível reconhecer algumas descontinuidades subhorizontais. Os ensaios de perda d'água sob pressão revela- 
ram baixa permeabilidade do maciço, com valores máximos sempre inferiores a $10^{-5} \mathrm{~cm} / \mathrm{s}$.

Após a perfuração dos poços tubulares, foram realizadas perfilagens de resistividade elétrica (normal longa 64") e de gama natural. As medidas no pacote sedimentar foram realizadas antes da colocação dos tubos de revestimento de PVC geomecânico, as quais servirão como modelo de calibração para as futuras medições nos poços instalados na área de testes controlados de geofísica rasa do IAG.

A Figura 3 mostra 0 resultado das perfilagens gama natural e de resistividade elétrica para os poços P1, P2 e P3, interpretadas com base na correlação dos perfis litológicos dos poços. Nas perfilagens gama os maiores níveis de radiação correspondem às argilas puras, enquanto que os mais baixos estão relacionados com as formações arenosas. Por outro lado, nas perfilagens elétricas os maiores valores de resistividade correspondem às formações arenosas e os menores estão relacionados com as formações argilosas. Os resultados geofísicos obtidos comparados com as informações diretas provenientes dos poços permitiram que as ambigüidades que persistiam fossem esclarecidas (Borges \& Porsani, 2001; Borges, 2002).

\section{INVESTIGAÇÕES GEOFÍSICAS DE SUPERFÍCIE}

Os perfis geofísicos foram adquiridos ao longo de uma linha com $200 \mathrm{~m}$ de comprimento, na direção NW - SE (Figura 1). A seguir serão abordados os aspectos envolvidos na aquisição e processamento dos dados geofísicos.

\section{MÉTODOS SíSMICOS}

A aquisição de dados para 0 método de refração sísmica foi dimensionada para investigar os primeiros metros em subsuperfície. Para o imageamento do topo do embasamento da Bacia empregou-se o método de reflexão. Os levantamentos sísmicos de refração e reflexão foram planejados de modo a cobrir a mesma área em subsuperfície, possibilitando que o modelo superficial determinado pelo método de refração fosse incorporado na interpretação dos dados de reflexão para a obtenção do modelo final em profundidade. A aquisição dos dados foi efetuada com um sismógrafo de 24 canais da OYO-Geospace com sistema de aquisição DAS-1, geofones de freqüência natural $100 \mathrm{~Hz}$ e uma marreta de $7 \mathrm{~kg}$ sobre uma placa de metal como fonte de energia sísmica.

\section{Refração rasa}

Foram executados dois perfis de refração de $72 \mathrm{~m}$ de comprimento com espaçamento entre receptores de $1 \mathrm{~m}$. Cada perfil é 0 resultado da aquisição de dois pontos de tiro fixados em cada uma das extremidades (dois tiros diretos e dois reversos). Duas aquisições adicionais foram efetuadas com o afastamento mínimo de $1 \mathrm{~m}$ para se observar a variação de velocidade da onda direta ao longo do perfil e determinar por interpolação uma função de velocidade para 0 cálculo da espessura da primeira camada. $\mathrm{Na}$ Figura 4a são representadas as posições dos pontos de tiro e os tempos das primeiras quebras dos sismogramas; os círculos representam as leituras para os tiros internos e os triângulos cheios para os tiros externos. Os triângulos abertos correspondem à extrapolaçãa dos tempos dos tiros externos para os tiros internos pelo princípio do paralelismo, técnica também conhecida como phantoming (Lankston \& Lankston, 1986).

As velocidades da onda direta variaram de $370 \mathrm{~m} / \mathrm{s}$ a $520 \mathrm{~m} / \mathrm{s}$, conforme indicado na Figura 4b. Os perfis, interpretados com 0 método recíproco (Palmer, 1986), forneceram uma camada superficial de espessura relativamente constante, variando de 4,5 a $5,5 \mathrm{~m}$ e uma velocidade de $1650 \mathrm{~m} / \mathrm{s}$ para 0 topo da camada subjacente (Figura 4b).

\section{Reflexão rasa}

Testes de campo para análise de ruído ( walkaway noise test) foram executados para avaliar a resposta sísmica do terreno e para selecionar a janela de afastamentos fonte-receptor ideal para se observar a reflexão no topo do embasamento da Bacia livre da interferência dos demais eventos coerentes registrados. 0 afastamento mínimo ideal foi identificado em $50 \mathrm{~m}$ e 0 afastamento máximo de $74 \mathrm{~m}$, foi estabelecido em função da técnica de aquisição adotada para atingir a multiplicidade CMP (Commom Mid Point) de $1200 \%$, com um espaçamento entre geofones e entre pontos de tiro de $1 \mathrm{~m}$.

A técnica adotada para aquisição CMP foi a mesma empregada por Le Diagon \& Diogo (1999), a qual foi estabelecida para reduzir o tempo de execução do levantamento de campo, em função do número limitado de canais de registro do sismógrafo. 0 procedimento consiste em manter fixo 0 arranjo de geofones e mover o ponto de tiro na direção do arranjo. Após executados 12 pontos de tiro, 0 que equivale a metade do número de canais registrados, movem-se os primeiros 12 geofones para o final do arranjo, e prossegue-se com a execução de novos 12 pontos de tiro. Esse procedimento difere da técnica convencional por não manter o mesmo afastamento mínimo em todos os pontos de tiro 


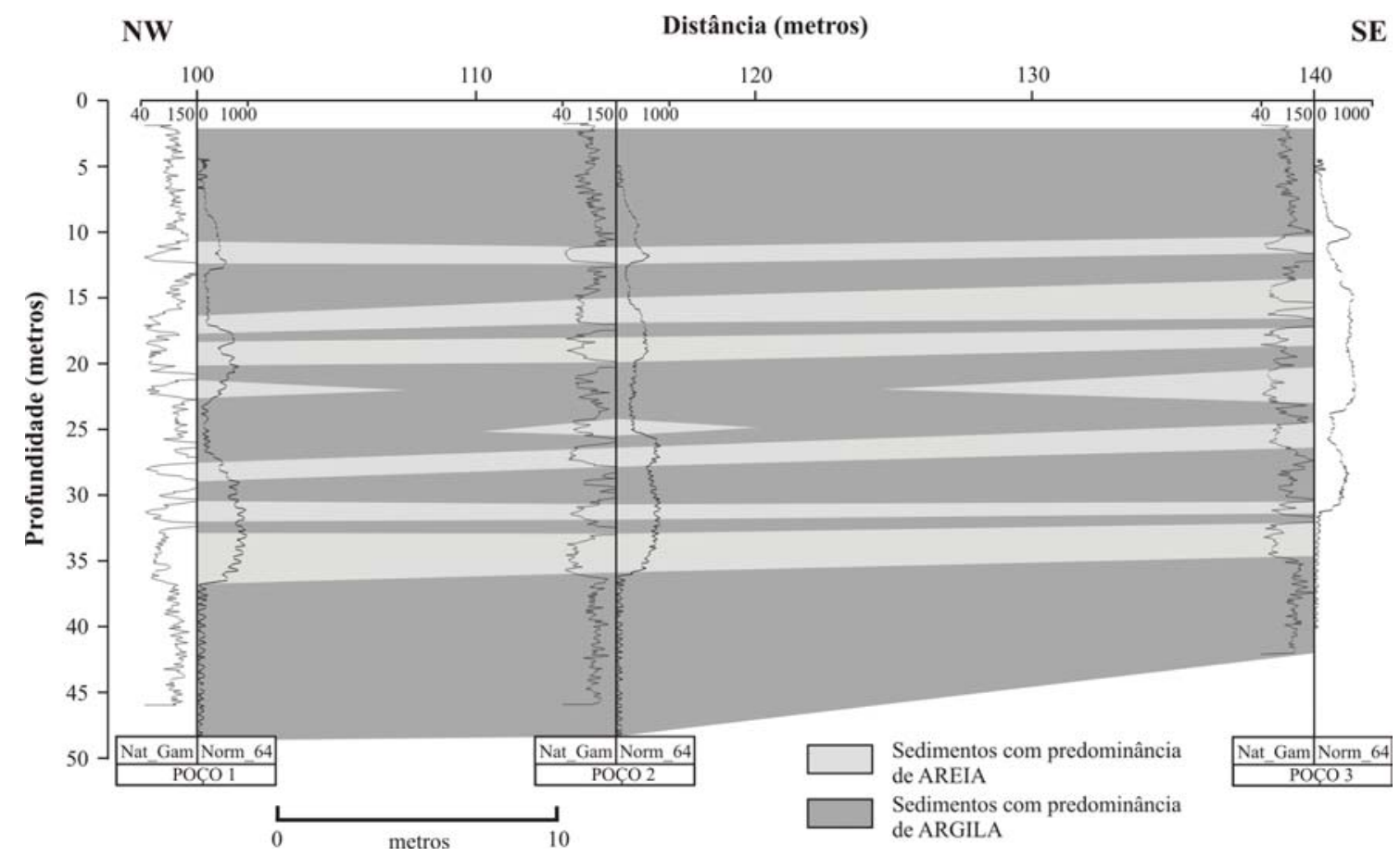

Figura 3 - Correlação entre as perfilagens geofísicas dos poços P1, P2 e P3 e as suas colunas litológicas.

Figure 3 - Correlation between geophysical well logging of the P1, P2 and P3 and their lithologic columns.
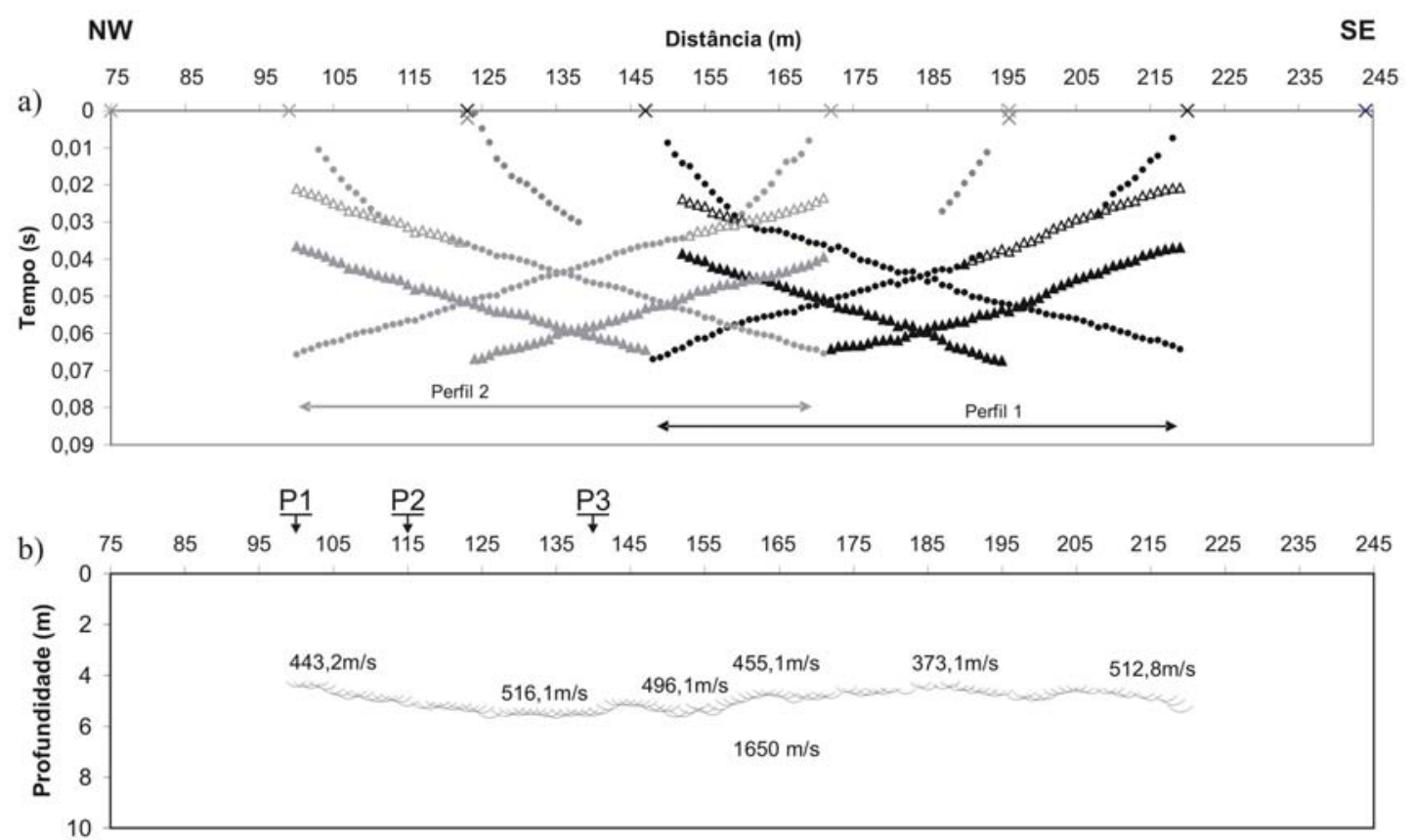

Figura 4 - a) Tempos de percurso dos perfis de refração (perfis 1 e 2). As posições dos pontos de tiro estão indicadas pelo símbolo "x". b) Interpretação da topografia do topo da zona saturada.

Figure 4 - a) Travel time of the refraction profiles (profiles 1 and 2). The positions of the shot points are indicated by symbol " $x$ ". b) Topography interpretation of the saturated zone top. 
do levantamento, para tal seria necessário mover um geofone para o final do arranjo após a execução de cada ponto de tiro.

Os tempos de percurso das reflexões registradas dentro da janela de afastamentos fonte-receptor utilizada estão fora da validade da aproximação hiperbólica (Dix, 1955), convencionalmente empregada para a análise de velocidades. Além disso, o sinal refletido apresenta uma defasagem na sua forma de onda, devido à reflexão ocorrer acima do ângulo crítico de incidência, 0 que também afeta o processo de análise de velocidades. Uma nova metodologia foi proposta para lidar com as reflexões acima do ângulo crítico, na determinação do modelo intervalar de velocidades sísmicas, integrando as informaç̧ões extraídas dos dados de refração (Figura 4b) e a modelagem elástica das reflexões (Diogo et al., 2003).

0 restante do processamento, realizado com o software Seismic Unix - SU (Cohen \& Stockwell, 2000), seguiu as etapas tradicionais do processamento de dados de reflexão sísmica, citadas na Tabela 1. 0 perfil resultante com $120 \mathrm{~m}$ de comprimento (Figura 5) mostra uma excelente concordância entre a profundidade obtida para o topo do embasamento e a informação dos poços.

\section{ELETRORRESISTIVIDADE}

Com o objetivo de determinar um modelo geoelétrico e o topo do embasamento para a área do Sítio Controlado de Geofísica rasa do IAG/USP, foram realizadas oito sondagens elétricas verticais (SEV's) com arranjos Schlumberger (SS), três com arranjos dipolares (SD) e dois perfis de caminhamento elétrico com arranjo dipolo-dipolo de 10 e 20 m. A Figura 1 mostra a localização das SEV's e dos perfis de caminhamento elétrico.

\section{Sondagens Elétricas Verticais - SEV's}

Os dados foram adquiridos com um equipamento Syscal R2, empregando-se corrente chaveada com tempo de injeção de 2 segundos e foi considerada uma média da integração de 10 medidas. Para a interpretação quantitativa dos dados das SEV's foram adotados modelos de camadas horizontais, ajustando os dados de resistividade aparente, através do algoritmo de inversão 1D com o software RESIXIP (Interpex).

É importante ressaltar que os modelos geoelétricos obtidos da inversão 1D dos dados não são únicos. Com o objetivo de diminuir a ambigüidade na interpretação das sondagens, no processo de inversão foram utilizados vínculos geológicos provenientes das perfurações dos três poços (Figura 2). Dessa forma, primeiro foi realizada a interpretação qualitativa e estabelecimento do modelo inicial, seguido do processo de inversão com o soft- ware citado. 0 modelo obtido foi comparado com as informações dos poços e os contatos das camadas de alta resistividade foram utilizados como parâmetros para refinar o resultado.

A Figura 6 mostra a curva de resistividade aparente para a sondagem SS01 com o modelo geoelétrico interpretado a partir das inversões $1 \mathrm{D}$ e das informaç̧ões geológicas provenientes dos poços.

Os resultados das SEV's adquiridas com 0 arranjo Schlumberger indicaram a presença de um condutor profundo. Nas colunas litológicas dos poços (Figura 2) observa-se um pacote sedimentar de aproximadamente $40 \mathrm{~m}$ de espessura, caracterizado por camadas de areia fina alternando-se com camadas argilosas, estando 0 embasamento cristalino capeado por uma camada de argila de aproximadamente $15 \mathrm{~m}$ de espessura. A areia fina é bastante friável, porosa e permeável, tendo as características de um excelente aqǘfero, portanto, bastante condutora. Além disso, a presença da argila pode aumentar a condutividade do pacote sedimentar. Deste modo, esta espessa zona condutora (areia saturada e argila) reduz significativamente a penetração da corrente, não permitindo identificar o topo da rocha granito-gnáissica.

Para investigar profundidades maiores foram feitas SEV's com arranjos dipolares (SD), pois a profundidade de penetração alcançada pela sondagem dipolar supera a do arranjo Schlumberger (Orellana, 1972).

As sondagens dipolares foram realizadas com dipolos de $10 \mathrm{~m}$. A Figura 7 mostra a curva de resistividade aparente da sondagem SD03, com o respectivo modelo geoelétrico interpretado a partir das inversões $1 \mathrm{D}$ e das informações geológicas provenientes dos poços. Observam-se claramente, os mesmos horizontes geoelétricos da sondagem SS01, além de um forte resistor em $52 \mathrm{~m}$ de profundidade, interpretado como o topo do embasamento granito-gnáissico da Bacia de São Paulo.

\section{Caminhamento elétrico dipolo - dipolo}

Foram adquiridos dois perfis de caminhamento elétrico com arranjos dipolares: um com abertura dos dipolos de $10 \mathrm{~m}$ e 0 outro de $20 \mathrm{~m}$. Em ambos os perfis cinco níveis de profundidade foram investigados, permitindo atingir até cerca de $40 \mathrm{~m}$ de profundidade.

Para uma melhor caracterização e interpretação geológica da pseudo-seção de caminhamento elétrico com dipolos de $20 \mathrm{~m}$, os dados foram tratados através de software de modelagem 2D, visando definir as resistividades e as profundidades reais dos corpos geológicos investigados.

0 modelo inicial foi elaborado com base nas informações 
Tabela 1 - Etapas de processamento sísmico de reflexão.

Table 1 - Seismic reflection processing stages.

\begin{tabular}{|cl|}
\hline 1. & Edição dos dados \\
2. & Correção estática residual (com base no alinhamento das refrações) \\
3. & Agrupamento dos dados em sismogramas CMP \\
4. & Filtragem de frequência (filtro passa-banda 120-250 Hz) \\
5. & Análise de velocidades \\
6. & Correção de NMO \\
7. & Empilhamento \\
8. & Silenciamento das refrações que restaram após o empilhamento \\
9. & Migração \\
10. & Conversão tempo-profundidade \\
\hline
\end{tabular}

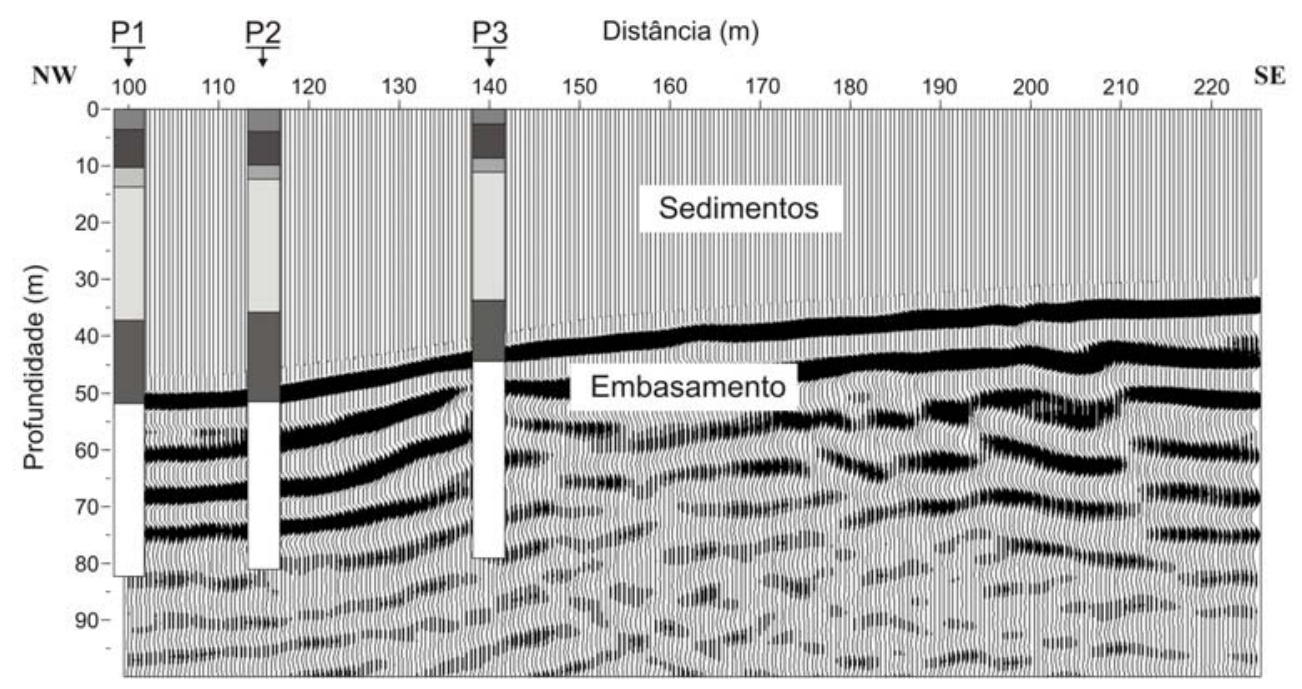

Figura 5 - Perfil de reflexão sísmica em profundidade, com as colunas litológicas dos poços sobrepostas.

Figure $\mathbf{5}$ - Seismic reflection profile in depth, with the wells lithologic columns overlapping.

geológicas provenientes dos poços e das SEV's existentes. A interpretação foi refinada através do software de modelagem poligonal 2D RESIXIP2Di (Interpex). Nesse programa, os vários polígonos utilizados são caracterizados por um valor constante de resistividade, e representam os corpos e as camadas geológicas existentes. Essa modelagem 2D para os valores de resistividade é baseada no método dos elementos finitos, no qual o modelo é construído a partir de uma seção dividida em células retangulares formando um grid que se estende lateralmente do primeiro eletrodo de corrente até o último eletrodo de potencial. Cada célula é representada por uma única resistividade. Na simulação matemática, a corrente é injetada em cada um dos nós da malha para cada profundidade teórica definida pela rede, sendo os ele- trodos de corrente usados para simular as voltagens nos eletrodos de potencial, e esses parâmetros são combinados para fornecer as resistividades aparentes na pseudo-seção. Por meio da observação da pseudo-seção e das informações obtidas nas SEVs e nos poços, foi construído um modelo 2D com vários polígonos que representam os corpos geológicos com diferentes resistividades. 0 processo de interpretação é feito via modelagem direta. 0 ajuste entre o modelo sintético e os dados de campo foi realizado interagindo com os valores de resistividade e o formato dos polígonos até que as pseudo-seções de campo e sintética apresentassem características similares. A Figura 8 mostra 0 resultado da modelagem 2D do perfil de caminhamento elétrico com dipolos de 20 m, onde são apresentados: a pseudo-seção de re- 


\section{Curva de Campo - SS01}

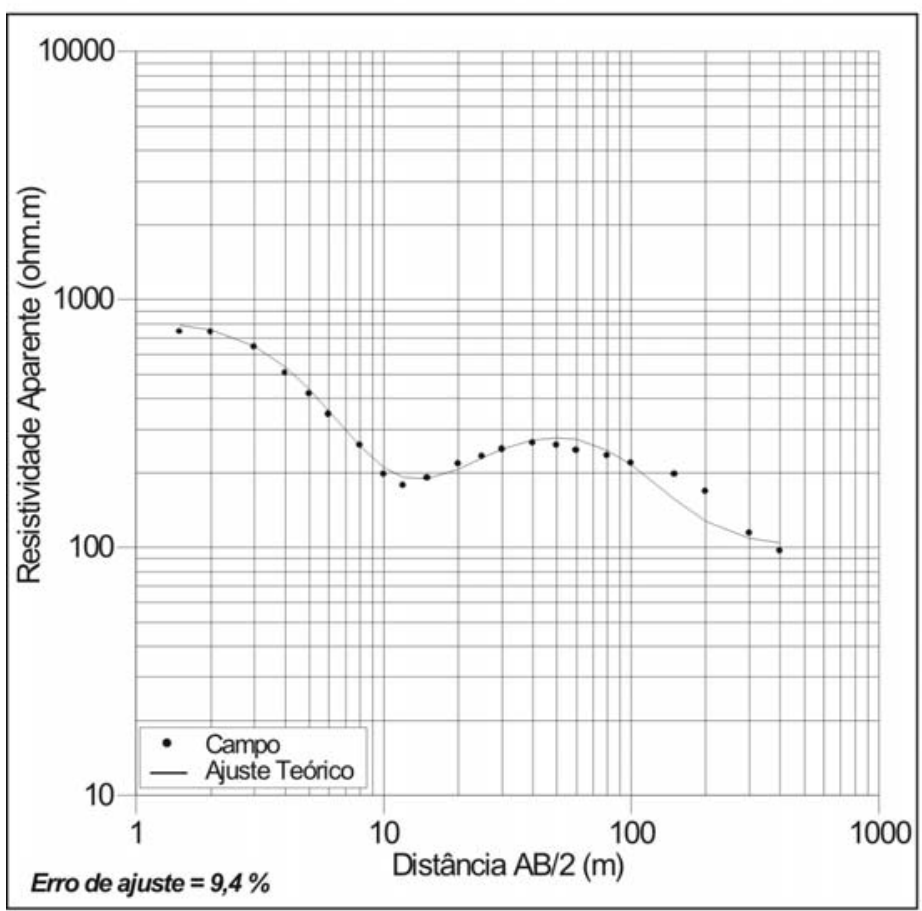

Coluna Geoelétrica

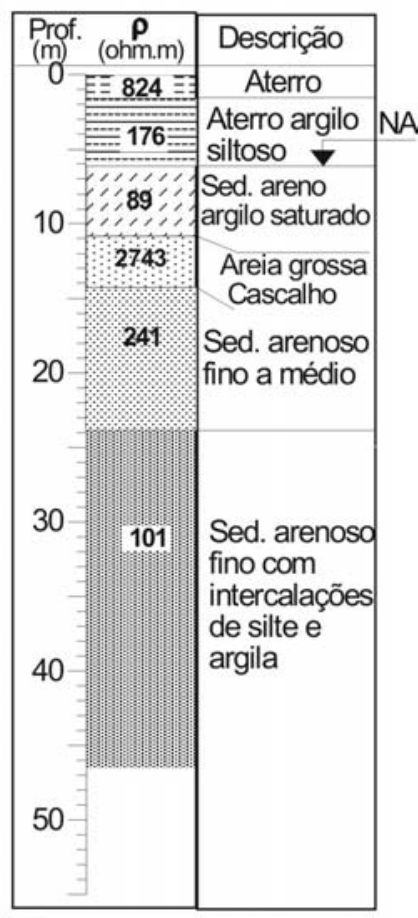

Figura 6 - Curva de resistividade aparente da sondagem Schlumberger SS01, com o modelo geoelétrico interpretado a partir das inversões 1D e informações dos poços.

Figure 6 - Apparent resistivity curve of the SSO1 Schlumberger sounding, with the geoelectric model interpreted from the 1D inversions and wells information.

sistividade aparente de campo (Figura 8a), a seção de resistividade aparente sintética (Figura 8b) e o modelo geoelétrico interpretado (Figura 8c). 0 modelo geoelétrico mostra os vários estratos sedimentares existentes e, uma zona mais condutora entre as distâncias de 60 e 80 m.

Para a abertura de $20 \mathrm{~m}$ dos eletrodos, a modelagem 2D não permite a distinção das camadas sedimentares com o mesmo detalhe da SEV, ou seja, em alguns casos uma ou mais camadas visualizadas na SEV aparecem agrupadas no modelo 2D. 0 topo do embasamento não pode ser delimitado em razão da profundidade limite de penetração.

\section{GPR - GROUND PENETRATING RADAR}

Com o objetivo de imagear em detalhe a estratigrafia da subsuperfície rasa na área do Sítio Controlado do IAG/USP, quatro perfis de reflexão GPR com afastamento constante foram adquiridos utilizando-se antenas de 25, 50, 100 e 200 MHz (Figura 1).

Para a aquisição dos dados GPR foi utilizado o equipamento sueco RAMAC-MALA. Nos perfis de reflexão obtidos com as antenas de 25, 50, 100 e $200 \mathrm{MHz}$, os espaçamentos entre as an- tenas transmissora e receptora, foram de 4, 2, 1 e $0.6 \mathrm{~m}$, respectivamente. 0 intervalo de medida foi de $1 \mathrm{~m}$ para as antenas de $25 \mathrm{MHz}$ e de $0.5 \mathrm{~m}$ para as demais antenas. Para obter a melhor razão sinal/ruído foram realizados vários testes de campo utilizando-se empilhamentos de 32, 256, 512 e 1024, sendo que o valor ótimo de 512 foi utilizado na aquisição dos perfis GPR.

Os perfis de $200 \mathrm{~m}$ de comprimento estão sobrepostos visando fornecer uma boa penetração da onda de radar com as antenas de $25 \mathrm{MHz}$ e uma boa resolução com as antenas de $200 \mathrm{MHz}$.

Sobre os perfis de reflexão foram adquiridas seis sondagens de velocidade do tipo CMP - Common Mid Point, utilizandose antenas de 50, 100 e $200 \mathrm{MHz}$. A velocidade da onda eletromagnética em subsuperfície de $0,08 \mathrm{~m} / \mathrm{ns}$ foi determinada da análise das sondagens CMP pelo método Semblance (Yilmaz, 1987). As medidas da profundidade da camada de areia grossa encontrada no poço-P3 e do tempo do refletor correspondente no radargrama também foram utilizadas para o cálculo da velocidade. A velocidade de propagação encontrada é compatível com um sedimento argiloso saturado (Porsani, 1999) e foi utilizada para a conversão dos perfis de reflexão de tempo para profundidade. 

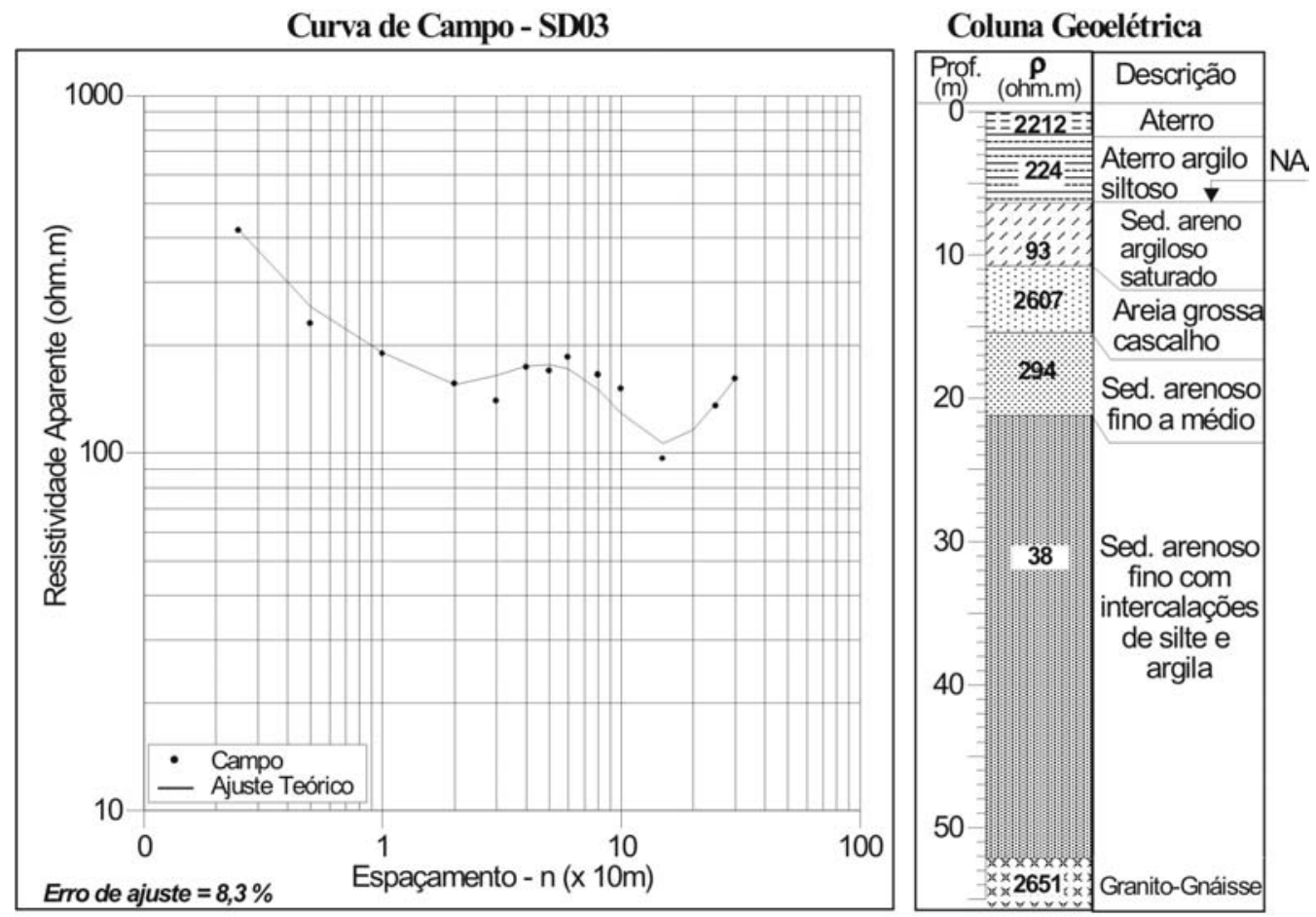

Figura 7 - Curva de resistividade aparente da sondagem dipolar SD03, com o modelo geoelétrico interpretado a partir das inversões 1D e informações dos poços.

Figure 7 - Apparent resistivity curve of SDO3 dipole sounding, with the geoelectric model interpreted from the 10 inversions and wells information.

Os dados GPR foram processados utilizando-se 0 software GRADIX (Interpex). Neste trabalho são apresentados somente os perfis de reflexão obtidos com as antenas de 25 e $50 \mathrm{MHz}$, devido à maior profundidade de penetração alcançada. Os resultados obtidos estão correlacionados com os perfis litológicos dos três poços.

A Figura 9 mostra o perfil GPR com antenas de $25 \mathrm{MHz}$, sobreposto com os perfis litológicos dos três poços. Dois refletores são observados nitidamente: um mergulhando para NW e 0 outro, mais longo, mergulhando suavemente para SE. Com as antenas de $25 \mathrm{MHz}$ esperava-se obter informações da subsuperfície até 30 $-40 \mathrm{~m}$ de profundidade. Entretanto, as informações ficaram limitadas em torno de $16 \mathrm{~m}$ de profundidade, devido à condutividade dos materiais em subsuperfície.

0 perfil GPR da Figura 10, obtido com antena de $50 \mathrm{MHz}$, foi sobreposto aos perfis litológicos dos três poços. Fortes refletores com características bem heterogêneas, até cerca de $5 \mathrm{~m}$ de profundidade estão presentes. A base desses refletores coincide com 0 topo do horizonte saturado identificado pela sísmica de refração (Figura 4b). As informações das colunas litoestratigráficas dos poços mostram que este horizonte corresponde à base de um aterro e início da zona saturada, estando o nível freático entre 5 e $7 \mathrm{~m}$ de profundidade. Além disso, estão identificados dois refletores: um mergulhando para NW (entre 50 e $100 \mathrm{~m}$ ) e, 0 outro suavemente para SE.

Para verificar a natureza do refletor mergulhando para NW, entre 5 e $7 \mathrm{~m}$ de profundidade (Figuras 9 e 10), nas coordenadas 50 a $100 \mathrm{~m}$, foram realizados dois perfis de reflexão: paralelo e perpendicular ao prédio do Instituto de Física. A análise desses perfis permitiu concluir que o refletor mergulhando para NW é provocado pela presença deste prédio, devido à propagação da onda eletromagnética que viaja no ar (onda aérea) que reflete na parede do prédio e retorna para a antena receptora do sistema GPR.

0 refletor com suave mergulho para SE variando de 7 a $11 \mathrm{~m}$ de profundidade está relacionado com uma camada de areia grossa-cascalho com presença de elevada concentração de óxidos de ferro. Esta interpretação está baseada na descrição litológica das amostras dos poços (Figura 2) e na análise dos resultados das perfilagens geofísicas dos poços (Figura 3).

\section{INTEGRAÇÃO DOS RESULTADOS E CONCLUSÕES}

Os resultados geofísicos de superfície e de poço foram comparados com as informações das colunas litoestratigráficas dos três poços perfurados. De um modo geral, os resultados obtidos com 


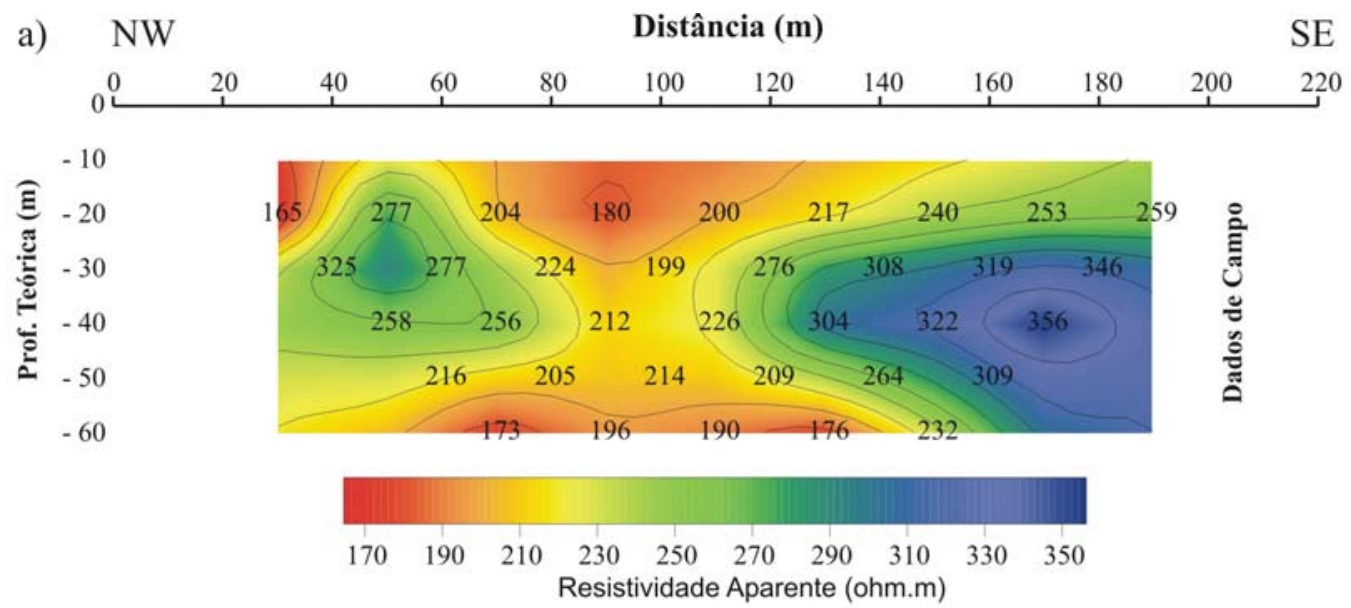

b)
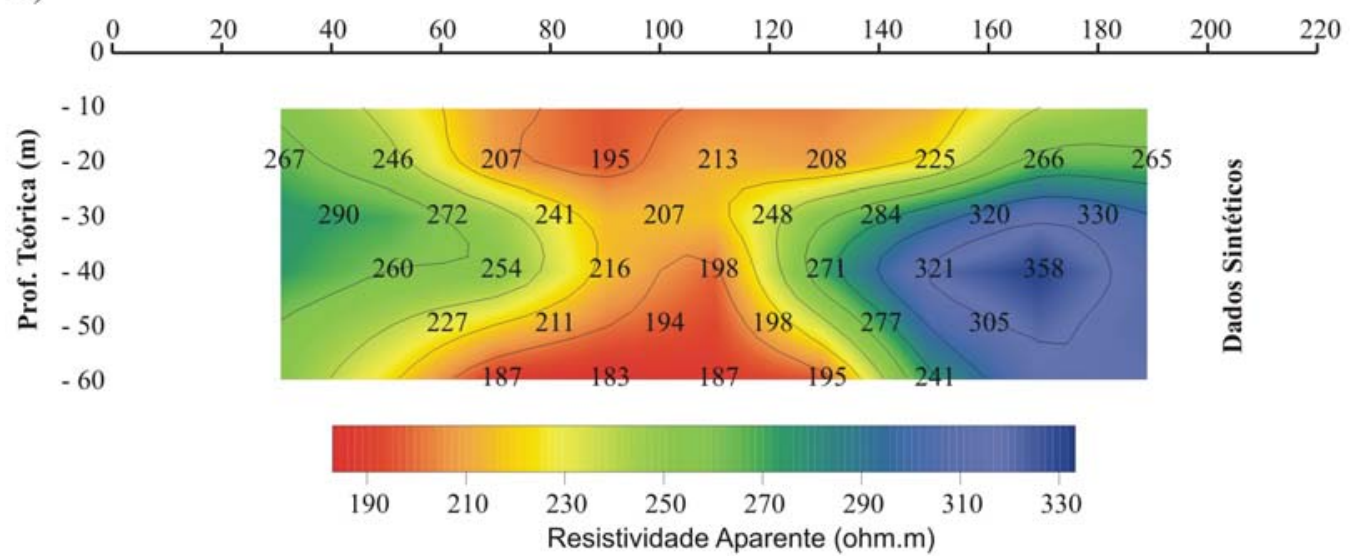

c)

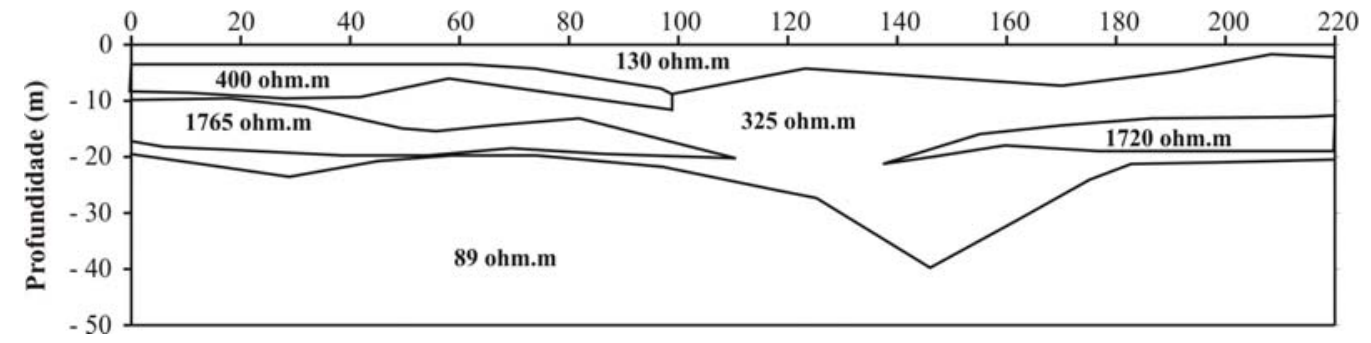

Figura 8 - Resultado da modelagem 2D do perfil de caminhamento elétrico com dipolos de $20 \mathrm{~m}$. a) Pseudo-seção de resistividade aparente; b) Seção de resistividade aparente sintética e c) Modelo geoelétrico interpretado.

Figure 8 - 2D modeling result of the electric survey with $20 \mathrm{~m}$ dipolo. a) Apparent resistivity pseudosection; b) Synthetic apparent resistivity section and c) Geoelectric model interpreted.

vários métodos geofísicos apresentaram uma boa concordância e uma boa correlação com as informações geológicas provenientes dos poços.

Os refletores observados nos perfis GPR (Figuras 9 e 10) foram correlacionados com os horizontes geológicos obtidos dos poços. 0 forte refletor em torno de $5 \mathrm{~m}$ de profundidade corres- ponde ao início da zona saturada, que equivale à base do aterro, e está concordante com o resultado da sísmica de refração (Figura 4b). Além disso, o refletor em torno de $12 \mathrm{~m}$ de profundidade, entre 90 e $160 \mathrm{~m}$, tem uma nítida correspondência com uma camada de $2 \mathrm{~m}$ de espessura caracterizada por uma areia grossa-cascalho (Figura 2). A descrição litológica dos poços e medidas de sus- 


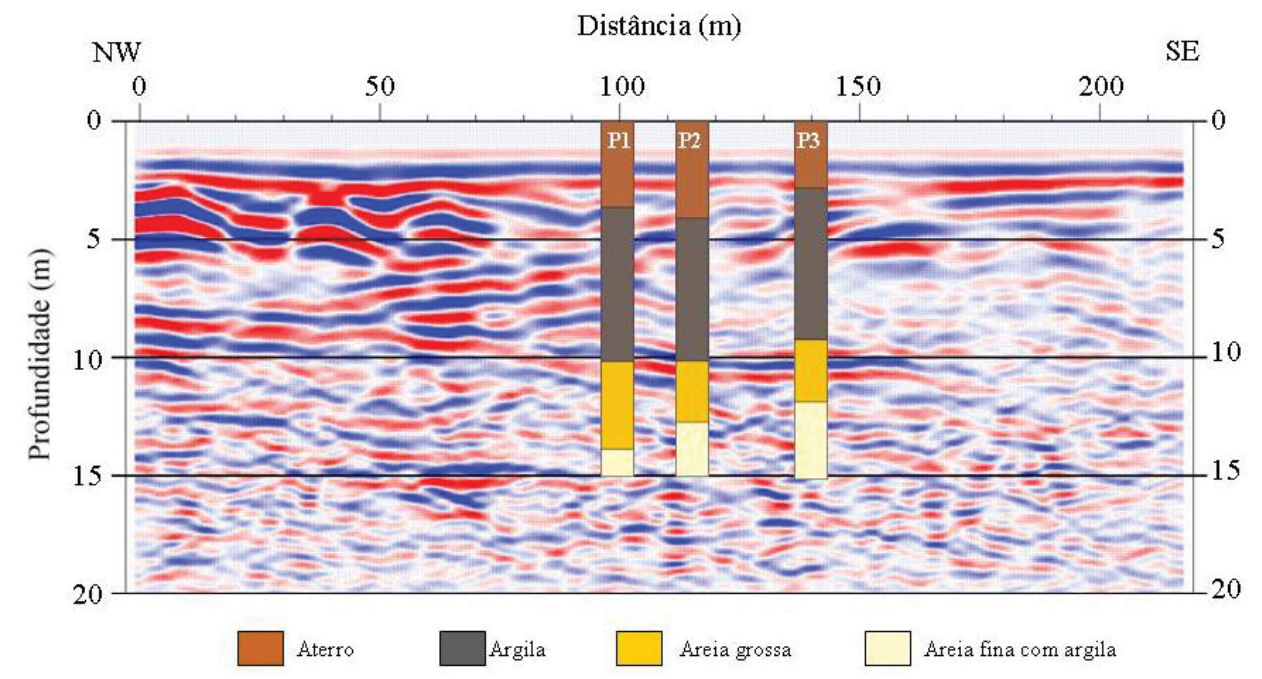

Figura 9 - Perfil GPR obtido com as antenas de $25 \mathrm{MHz}$ e os perfis litológicos dos poços sobrepostos.

Figure $\mathbf{9}$ - GPR profile obtained with $25 \mathrm{MHz}$ antennas and overlapping wells lithologic profiles.

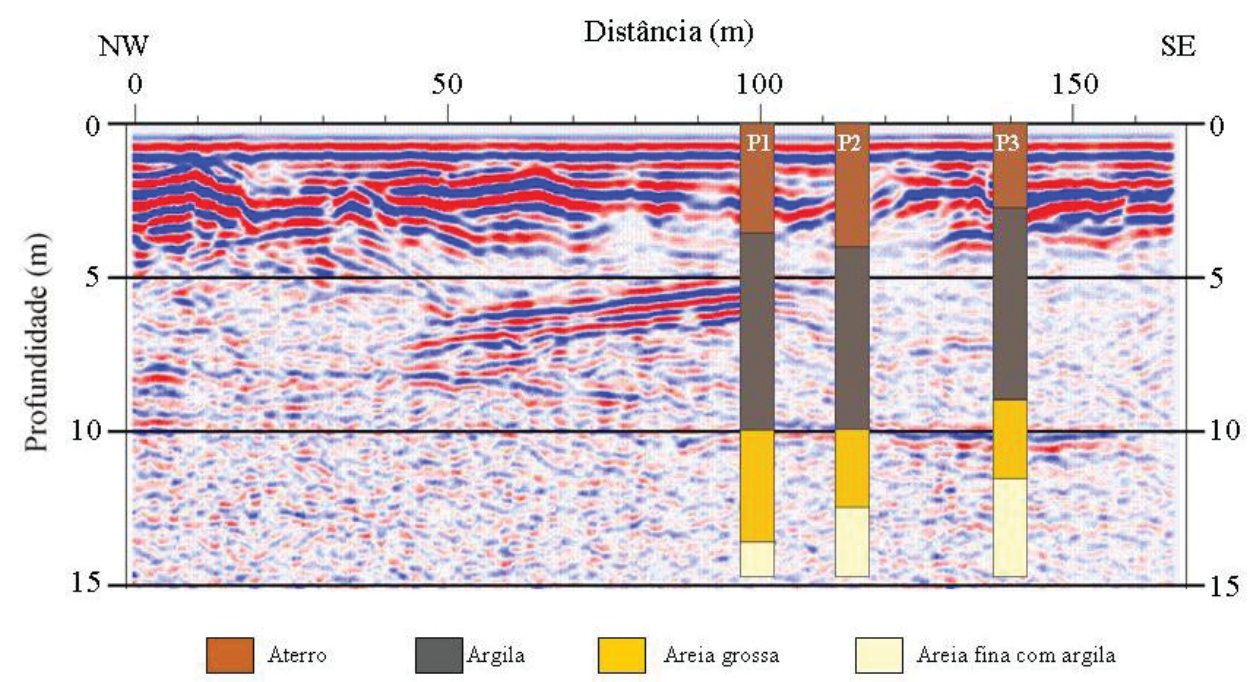

Figura 10 - Perfil GPR obtido com as antenas de $50 \mathrm{MHz}$ e os perfis litológicos dos poços sobrepostos.

Figure 10 - GPR profile obtained with $50 \mathrm{MHz}$ antennas and overlapping wells lithologic profiles.

cetibilidade magnética nas amostras dos sedimentos do poço P3 constatou a presença de óxidos de ferro nessa camada de areia grossa, que pode causar reflexões nos perfis GPR (Van Dam et al., 2002).

Um fraco refletor está presente em torno de $10 \mathrm{~m}$ de profundidade, entre 0 e $80 \mathrm{~m}$, ligeiramente inclinado para SE, que pode ser uma continuação desta camada de areia grossa, mais rasa para 0 início do perfil. 0 refletor inclinado para NW identificado, entre 50 e 100 m, é devido a uma fonte de interferência situada na su- perfície, relacionada com a parede do prédio do Instituto de Física (Borges \& Porsani, 2001).

0 topo do embasamento da Bacia Sedimentar de São Paulo na área de estudos está localizado em torno de $53 \mathrm{~m}$ de profundidade e é caracterizado por granito-gnáisses (Figura 2). 0 seu reconhecimento foi possível através do método de reflexão sísmica rasa (Figura 5) e pelas sondagens elétricas verticais com arranjos dipolares (Figura 7).

0 modelo geoelétrico 2D obtido a partir do perfil de cami- 
nhamento elétrico com dipolos de $20 \mathrm{~m}$ apresentou um excelente ajuste com a pseudo-seção (Figura 8). Nesta figura observa-se claramente uma variação lateral de resistividade e a presença de duas cunhas de materiais mais resistivos. Segundo informações das colunas litológicas dos poços essas cunhas resistivas estão relacionadas com areias grossas com presença de óxidos de ferro (Figura 2).

No modelo obtido com a magnetometria (Mendonça et al., 1999), a posição do topo dos prismas apresenta uma boa correlação com a posição das duas regiões anômalas resistivas encontradas no perfil de caminhamento eletromagnético. Além disso, o seu topo coincide com as cunhas de areias com óxidos de ferros, encontradas no modelo geoelétrico (Figura 8) e com 0 horizonte refletor que ocorre nos perfis GPR em torno de $11 \mathrm{~m}$ de profundidade (Figuras 9 e 10).

Os perfis litológicos dos poços permitiram identificar intercalações de sedimentos areno-argilosos e 0 topo do embasamento granito-gnáisse para este ponto da Bacia de São Paulo. As informações mais rasas até cerca de $20 \mathrm{~m}$ de profundidade, foram fundamentais para a calibração e a interpretação geológica dos perfis geofísicos obtidos com os métodos GPR, sísmica de refração e caminhamento elétrico. 0 topo do embasamento da Bacia variou de $46 \mathrm{~m}$ (poço P3), $52 \mathrm{~m}$ (poço P2) e $53 \mathrm{~m}$ (poço P1). Estas informações obtidas diretamente dos poços foram importantes para comprovar os resultados do perfil sísmico de reflexão rasa e das sondagens elétricas verticais com arranjos dipolares, bem como reduzir as ambigüidades existentes.

Os poços perfurados permitirão testar, em condições controladas de campo, novas metodologias de geofísica de superfície, de poço e de combinações superfície-poço, e também servirão de referência litológica para os futuros trabalhos de geologia e de geofísica que vier a serem realizados na área do Sítio Controlado de Geofísica Rasa do IAG, no campus universitário da USP.

A interpretação integrada das investigações geofísicas e das informações litológicas dos poços permitiu obter um modelo geológico/geofísico confiável para o local investigado na borda da Bacia Sedimentar de São Paulo. Os resultados apresentados ilustram a importância da integração de diversos métodos geofísicos na solução de um problema geológico em área urbana.

\section{AGRADECIMENTOS}

À FAPESP (Processos Nos. 99/12215-2 e 99/12217-5) pelo apoio financeiro. Ao Departamento de Geofísica do IAG pela infraestrutura necessária para a realização desta pesquisa. Aos colegas Carlos Alberto Mendonça e Marcelo Sousa de Assumpção
(IAG) pela leitura crítica do texto e da DIGE0/IPT pelas proveitosas discussões técnicas e descrição das amostras dos poços. Ao técnico Ernande Costa Santos e aos alunos da Graduação e da Pós-Graduação em Geofísica, pela participação ativa na aquisição dos dados.

\section{REFERÊNCIAS}

BORGES WR. 2002. Investigações geofísicas na borda da bacia sedimentar de São Paulo. Dissertação de Mestrado - Departamento de Geofííca, Instituto de Astronomia, Geofísica e Ciências Atmostéricas, Universidade de São Paulo, IAG/USP. São Paulo, 153p.

BORGES WR \& PORSANI JL. 2001. Investigações geofísicas na borda da bacia sedimentar de São Paulo. Anais do VII International Congress of the Brazilian Geophysical Society. SBGG - Salvador. CD-ROM.

BORGES WR \& PORSANI JL. 2003. Caracterização geofísica rasa do sítio controlado do IAG-USP: resultados preliminares. Anais do VIII International Congress of the Brazilian Geophysical Society. SBGf - Rio de Janeiro. CD-ROM.

COHEN JK \& STOCKWELL Jr. JW. 2000. CWP/SU: Seismic Unix Release 33: a free package for seismic research and processing. Center for Wave Phenomena, Colorado School of Mines.

DIOGO LA, LE DIAGON FMM \& PRADO RL. 2003. Integrating postcritical shallow seismic reflection and seismic refraction data. Submetido à revista Journal of Applied Geophysics.

DIX CH. 1955. Seismic velocities from surface measurements. Geophysics, 20: 68-86.

IRITANI MA, REBOUÇAS AC, HASSUDA S, DUARTE U, ELLERT N, MENDES JMB, ROSS SD \& MARCELINO M. 1990. Potencial hidrológico no campus da USP-São Paulo. Anais do VI Congresso Brasileiro de Águas Subterrâneas. Porto Alegre, 15-20.

IRITANI MA. 1993. Potencial hidrológico da cidade universitária de São Paulo. Dissertação de Mestrado - Instituto de Geociências, Universidade de São Paulo, IGc/USP. São Paulo, 63 p.

LANKSTON RW \& LANKSTON MM. 1986. Obtaining multilayer reciprocal times through phantoming. Geophysics, 51: 45-49.

LE DIAGON FMM \& DIOGO LA. 1999. Comparação entre diferentes técnicas de reflexão sísmica rasa para mapeamento do topo rochoso. Anais do VI International Congress of the Brazilian Geophysical Society. SBGf, Rio de Janeiro. CD-ROM.

LE DIAGON FMM. 2000. Investigações sobre metodologias de aquisiç̧ão e interpretação de dados sísmicos de reflexão rasa para imageamento do topo rochoso. Dissertação de Mestrado - Departamento de Geofííca, Instituto de Astronomia, Geofísica e Ciências Atmostéricas, Universidade de São Paulo, IAG/USP. São Paulo, 82 p. 
MENDONÇA CA, DIOGO LA, PORSANI JL \& HIODO FY. 1999. Ensino de geofísica aplicada: 0 campus universitário como laboratório de exploração. Anais do VI International Congress of the Brazilian Geophysical Society. SBGf, Rio de Janeiro. CD-ROM.

ORELLANA E. 1972. Prospeccion geolectrica en corriente continua. Madrid: Paraninfo, $523 \mathrm{pp}$.

PALMER D. 1986. Refraction seismics. In: HELBIG K \& TREITEL S. Handbook of geophysical exploration. Seismic exploration, 13: Geophysical Press, 269 pp.

PORSANI JL. 1999. Ground Penetrating Radar (GPR): Proposta metodológica de emprego em estudos geológico-geotécnicos nas regiões de Rio Claro e Descalvado-SP. Tese de Doutorado - Instituto de Geociências e Ciências Exatas, Universidade Estadual Paulista. Rio Claro, 145 p.

RICCOMINI C. 1989. 0 rift continental do sudeste do Brasil. São Paulo. Tese de Doutorado - Instituto de Geociências, Universidade de São Paulo, IGc/USP. São Paulo, 256 p.
RICCOMINI C. 1992. Tectônica e sedimentação na Bacia de São Paulo. Anais do Seminário de problemas geológicos e geotectônicos na região metropolitana de São Paulo. ABAS/ABGE/SBG-SP, São Paulo, 21-45.

RODRIGUES SI \& PORSANI JL. 2003. Simulações GPR 2D para caracterizar tambores plásticos a serem enterrados no sítio controlado do IAGUSP: resultados preliminares. Anais do VIII International Congress of the Brazilian Geophysical Society. SBGf - Rio de Janeiro. CD-ROM.

TAIOLI F. 1992. Desenvolvimento e teste de sistema sismográfico de alta resolução. Tese de Doutorado - Instituto de Geociências, Universidade de São Paulo, IGc/USP. São Paulo, 119 p.

VAN DAM RL, SCHLAGER W, DEKKERS MJ \& HUISMAN JA. 2002. Iron oxides as a cause of GPR reflections. Geophysics, 67(2): (march-april) $536-545$

YILMAZ 0. 1987. Seismic data processing. Tulsa: Society of Exploration Geophysics Press, 526 pp.

\section{NOTAS SOBRE OS AUTORES}

Jorge Luís Porsani. Geólogo pelo Instituto de Geociências da UFBa (1987). Mestrado em Geofísica pelo Núcleo de Pesquisas Geofísicas Aplicadas à Prospecç̃a de Hidrocarbonetos da UFPa (1991). De 1991 a 1996, trabalhou como Geofísico no Centro de Pesquisas da PETROBRAS. Doutorado em Geociências e Meio Ambiente pelo Instituto de Geociências e Ciências Exatas da UNESP (1999). Desde 01/12/1998 é Docente do Departamento de Geofísica do IAG/USP, atuando com métodos geoelétricos aplicados à geologia, geotecnia, meio ambiente e arqueologia. Atualmente, é Vice Coordenador do Programa de Pós-Graduação em Geofísica e Coordenador do Projeto de Instalação do Sítio Controlado de Geofísica Rasa do IAG (Fapesp 02/07509-1).

Welitom Rodrigues Borges. Geólogo pelo Instituto de Ciências Exatas e da Terra da Universidade Federal de Mato Grosso (ICET/UFMT) em 2000. Em 2002 obteve 0 título de Mestrado em Ciências, área de Geofísica Aplicada, pelo Instituto de Astronomia, Geofísica e Ciências Atmosféricas da Universidade de São Paulo (IAG/USP). Atualmente está fazendo o Doutorado (bolsista Fapesp 02/07510-0) junto ao Programa de Pós-Graduação em Geofísica do IAG/USP, desenvolvendo a pesquisa "Caracterização geofísica de alvos rasos com aplicações no planejamento urbano, meio ambiente e arqueologia: Estudo sobre o sítio controlado do IAG/USP".

Vagner Roberto Elis. Graduado em Geologia em 1990 pela Universidade Estadual Paulista. Mestre em Geociências pela Universidade Estadual Paulista em 1993 desenvolvendo a dissertação "A aplicação da geofísica para análise do meio físico: Importância para elaboração de mapeamento geotécnico". Doutor em Geociências pela Universidade Estadual Paulista em 1999 defendendo a tese "Avaliação da aplicabilidade de métodos elétricos de prospecção geofísica no estudo de áreas utilizadas para disposição de resíduos". Docente do Departamento de Geofísica do Instituto de Astronomia, Geofísica e Ciências Atmosféricas da Universidade de São Paulo, com atuação nas áreas de Geofísica Aplicada a estudos ambientais e hidrogeológicos.

Liliana Alcazar Diogo. Graduada em Geofísica em 1989 pela Universidade de São Paulo (IAG/USP). Doutora em Geofisica em 1995, defendendo a tese intitulada "Otimização simplificada para inversão sísmica cinemática" na Universidade Federal da Bahia (PPPG/UFBA). Docente no Departamento de Geofísica do Instituto de Astronomia, Geofísica e Ciências Atmosféricas da Universidade de São Paulo, com atuação na área de Geofísica Aplicada empregando os métodos sísmicos.

Francisco Yukio Hiodo. Graduado em Física pelo Instituto de Física da Universidade de São Paulo-USP em 1972. Mestrado em Geofísica pelo Instituto de Astronomia, Geofísica e Ciências Atmosféricas (IAG-USP) em 1981. Doutorado em Geofísica pelo IAG-USP em 1990. Auxiliar de Ensino no IAG-USP em 1973. Professor Assistente em 1981. Professor Doutor do IAG-USP desde 1990. Atualmente é especialista em Instrumentação Geofísica nas áreas de: Paleomagnetísmo (magnetômetros rotativos e desmagnetizadores), Geofísica Nuclear (espectrômetros gama e emanômetros de radônio), Perfilagem de poços tubulares, Geotermometria e sensores de temperatura, Magnetômetros de precessão de prótons e fluxgate, Métodos geoelétricos e eletromagnéticos.

Antonio Marrano. Geólogo, formado em 1977 pelo Instituto de Geociências da Universidade de São Paulo. Mestre em Geotecnia pela Escola de Engenharia de São Carlos da USP, em 1997. Desde janeiro de 1978, vem desenvolvendo atividades de pesquisa e prestação de serviços no IPT, na área de investigação geológico-geotécnica de maciços, aplicada à obras civis, especialmente barragens e à estabilidade de taludes. Atualmente é chefe da Seção de Investigação de Maciços do Agrupamento de Geologia Aplicada a Obras da Divisão de Geologia.

Carlos Alberto Birelli. Graduado em Geologia em 1979 pela Universidade Estadual Paulista (UNESP-Rio Claro). Atua, desde janeiro de 1980, no Laboratório de Geofísica Aplicada do Instituto de Pesquisas Tecnológicas do Estado de São Paulo-IPT. Atualmente é pesquisador III com atuação na área de Geofísica Aplicada a estudos ambientais, hidrogeológicos e obras. 